\title{
On the cover of this Issue: In Situ SEM High Strain Rate Testing of Large Diameter Micropillars Followed by TEM and EBSD Postmortem Analysis by Z. Lin, D. J. Magagnosc, J. Wen, C.-S. Oh, S.-M. Kim, and H. D. Espinosa
}

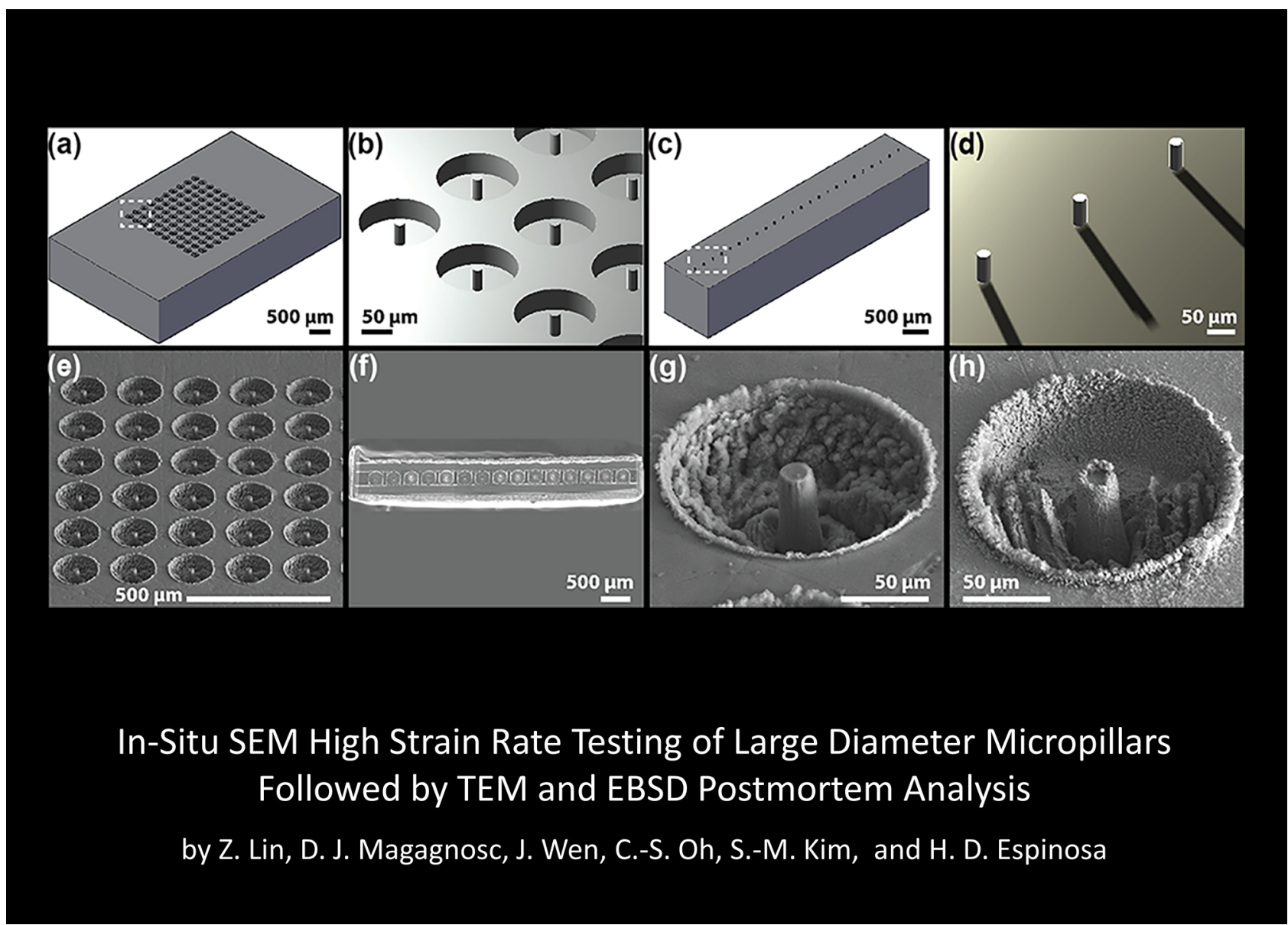

Publisher's Note Springer Nature remains neutral with regard to jurisdictional claims in published maps and institutional affiliations. 